\title{
Fortification of coconut oil with sesame oil through micro expeller extraction process
}

\author{
J.M.N. Marikkar ${ }^{1}$, J.M.M.A. Jayasundara ${ }^{1}$, W.S.R. Fernando ${ }^{2}$ and T.S.G. Peiris ${ }^{1}$
}

\begin{abstract}
Value addition to coconut oil is highly desirable in order to increase the range of coconut products. A study was conducted to formulate palatable coconut oil (CNO) blends enriched with essential fatty acid (EFA) using sesame seed as the supplementary source of EFA. For this purpose, micro-expelling process was employed to extract oil blends out of the dried coconut grating mixed with varying proportion of sesame seed (w/w; $0,1,2,3,4,5,7$ and 10\%). A sensory evaluation by a 30 -member semitrained panel was conducted using a seven-point hedonic scale in order to determine the critical limit of CNO fortification with sesame. Similarly, changes in fatty acid composition were determined using Gas Liquid Chromatography (GLC). Statistical analysis of the sensory data showed that a mild odor of sesame started to appear in the oil blends at 4\% level of sesame mixed with dried coconut gratings. According to fatty acid methyl ester (FAME) analysis, the relative increase in linoleic acid was only marginal although there was a substantial increase in unsaturated fatty acid component. At $5 \%$ level of fortification, the increment in linoleic acid was $9.2 \%$.
\end{abstract}

Key words: Essential fatty acid, virgin coconut oil, sesame, oil blends, sensory evaluation.

${ }^{1}$ Coconut Research Institute, Lunuwila, Sri Lanka.

2 Department of Food Science and Technology, Wayamba University of Sri Lanka, Makandura, Gonawila, Sri Lanka. 


\section{Introduction}

Coconut (Cocos nucifera L.) has been part of the peoples' diet and livelihoods in the tropical countries of Asia, and the Pacific for over a period of thousand years. It has got a wide range of uses to mankind. Particularly, the food value of coconut is enormous. The whitish kernel is the most valuable component of coconut nut. It is a wholesome food containing fat, protein, carbohydrates, minerals and vitamins. Therefore, it is used as a raw material in a range of food industries. Nearly fifty per cent of the coconut kernel is water (moisture). When dehydrated through kiln drying, the fresh kernel becomes copra, which is found to contain 68 per cent oil (Nathanael, 1966). Copra is subsequently used for oil extraction through traditional oil milling process. Due to poor practices in the traditional method of copra processing, coconut oil (CNO) thus obtained has got many quality related problems (Rodrigo et al., 1998). The oil looks brownish-yellow in color and sometimes tends to give off-flavors. However, recent studies highlighted the application of alternative technologies, which enhanced the CNO quality greatly. The oil thus obtained is colorless, limpid, and free from any kind of dirt that usually occurs in ordinary CNO produced out of copra (Beansch et al., 2004; Silveira et al., 2004).

Although the $\mathrm{CNO}$ with improved quality could play an important role as stable edible oil in many food applications, its multiple uses have to be extended through value additions. Value addition of $\mathrm{CNO}$ could be effected by way of fortifications with other materials to enhance its nutritional quality. Since lack of essential fatty acids in CNO is a disadvantage, it is proposed to fortify the oil with other minor oil seeds. Fortification of $\mathrm{CNO}$ with a suitable source rich in EFA is one of the more promising means of alleviating the deficiency of EFA in CNO. Sesame seed (Sesamum indicum L.), for instance, is an attractive option for this purpose as it is cheap and belongs to the high-fat seeds category with more than $50 \%$ of its dry matter being oil (Bockisch, 1998). Since it contains high proportion of linolenic acid, it can be profitably used for purpose of value addition (Deshpande et al., 1996). However, there is a possibility that the strong odor characteristics associated with sesame seed could be incorporated into $\mathrm{CNO}$ when it is used for fortification. From the sensory perspective, this odor may be unpalatable for certain segment of Sri Lankan consumers. Therefore, it is very useful to investigate the flavor changes of $\mathrm{CNO}$ with different levels of fortification of the oil with sesame. Hence, the objective of this study was to evaluate the consumer acceptance of the fortified blends of $\mathrm{CNO}$ in terms of different sensory attributes.

\section{Material and methods}

Materials: Desiccated coconut (DC) samples were obtained through dehydration of fresh disintegrated kernel at $70^{\circ} \mathrm{C}$. Sesame seed samples purchased from a grocery located at Lunuwila, were washed and oven dried at $70^{\circ} \mathrm{C}$ prior to use. All the chemicals used in this study were of analytical grade, unless otherwise specified.

Preparation of feed mixture (treatments) for oil extraction: DC and cleaned sesame seeds were weighed separately and mixed in different proportions. A total of eight treatments (mixtures) were prepared, $\mathrm{T}_{0^{-}}$100:0, $\mathrm{T}_{1^{-}}$99:1, $\mathrm{T}_{2^{-}}$98:2, $\mathrm{T}_{3^{-}}$97:3, $\mathrm{T}_{4^{-}}$96:4, $\mathrm{T}_{5^{-}}$95:5, $\mathrm{T}_{6^{-}}$93:7, $\mathrm{T}_{7^{-}}$90:10, (w/w) and identified by the mass ratio of DC to sesame seed.

Micro-expeller extraction of coconut oil: All the above treatments were fed one after the other into a micro-oil expeller for oil extraction. Extracted oil samples were collected in different buckets and kept for a week for sedimentation and filtration. The filtered samples were bottled into $500 \mathrm{ml}$ plastic bottles for further studies.

\section{Sensory evaluation methods}

Ranking test: Sensory evaluation was conducted to select more acceptable oil blends prepared out of the different treatments. Thirty semi-trained panelists (both males and females) of more than twenty years of age were asked to rank the eight coded samples of coconut oil 
according to their preference on sensory attributes namely, color, taste, smell and overall acceptability.

Testing criteria: The seven point Hedonic scale (1: dislike very much; 2: dislike; 3: dislike slightly; 4: neither like nor dislike; 5: like slightly; 6: like; 7: like very much) was used to evaluate degree of liking for each sensory attribute.

Serving the samples: The samples were heated at $50^{\circ} \mathrm{C}$ and coded with three digits random numbers, and served to the panelists in a random order. The panelists were asked to rinse their mouth after tasting each sample (AOCS, 1987).

Statistical analysis: The data of sensory evaluation were analyzed by Kruskal Wallis nonparametric test using Statistical Analysis System to find out significant differences between treatments (SAS, 1998). Linear regression analysis was carried out to find the association between the levels of sesame content and \% of fatty acid composition.

\section{Analytical methods}

Iodine value: Iodine values of oil samples were determined according to Wijs method as described in the Official Methods and Recommended Practices of the American Oil Chemists' Society (AOCS, 1987).

Fatty acid methyl ester (FAME) analysis: FAME were prepared by dissolving oil sample $(50 \mathrm{mg})$ with petroleum ether $(0.8 \mathrm{ml})$ and sodium methoxide (1M, $0.2 \mathrm{ml}$ ) (PORIM Test Method) and analyzed (in duplicate) on a Agillent 4890D gas chromatograph (Agillent Technologies, Singapore) equipped with a Flame Ionization Detector (FID). A non-polar capillary column HP-5 MS (0.25 mm internal diameter, 30 m length and $0.25 \mu \mathrm{m}$ film thickness, Hewlett Packard Company, Singapore) was used at a column pressure of 10 bars. The initial temperature of the column was $100^{\circ} \mathrm{C}$ and was programmed to increase to $220^{\circ} \mathrm{C}$ at $4^{0} \mathrm{C} / \mathrm{min}$ and kept for $15 \mathrm{~min}$ at $220^{\circ} \mathrm{C}$. The temperatures of the injector and detector were maintained at $250^{\circ} \mathrm{C}$ and $275^{\circ} \mathrm{C}$, respectively (Jayasuriya, 2004).

\section{Results and discussion}

\section{Sensory evaluation of oil blends prepared out of different treatments}

Statistical analysis of the sensory data showed that the oil blends coming out of eight different treatments were significantly different $(p<0.05)$ for each of the sensory attribute (Table 1). Of these oil blends, $\mathrm{VCO}\left(\mathrm{T}_{0}\right.$-control) showed significantly higher scores for all four sensory attributes. The ranking order of treatments within each sensory attribute is shown in Table 2. The highest mean scores were recorded for $\mathrm{T}_{0}$ with respect to all four sensory attributes. The multiple comparisons between treatments showed that mean scores of $\mathrm{T}_{0}$ with respect to color, taste and overall acceptability were significantly higher $(\mathrm{p}<0.005)$ than those of $\mathrm{T}_{1}$. However, mean scores of $\mathrm{T}_{0}$ and $\mathrm{T}_{1}$ were not significantly different with respect to smell. Table 2 further showed the preference of the panelists with respect to each sensory attribute, it was decreasing with the increasing concentration of sesame in the oil blends. A notable feature is the fact that the changing order of preference looked almost similar for all the four sensory attributes. Only in the case of color the changing order was slightly different. From these observations, it can be confirmed that the most preferred treatment was $T_{0}$ followed by 
Table 1. Results of Kruskal Wallis test along with mean scores of sensory attributes of different oil blends ${ }^{1}$

\begin{tabular}{|c|c|c|c|c|c|c|c|c|c|c|}
\hline \multirow{2}{*}{$\begin{array}{l}\text { Sensory } \\
\text { attribute }\end{array}$} & \multirow[t]{2}{*}{$X^{2}$} & \multirow[t]{2}{*}{$\operatorname{Pr}>X^{2}$} & \multicolumn{8}{|c|}{ Means scores } \\
\hline & & & $\mathrm{T}_{0}$ & $\mathrm{~T}_{1}$ & $\mathrm{~T}_{2}$ & $\mathrm{~T}_{3}$ & $\mathrm{~T}_{4}$ & $\mathrm{~T}_{5}$ & $\mathrm{~T}_{6}$ & $\mathrm{~T}_{7}$ \\
\hline Color & 25.71 & 0.0006 & 163.94 & 131.01 & 116.40 & 119.30 & 124.51 & 124.56 & 96.81 & 82.40 \\
\hline Smell & 79.78 & $<0.0001$ & 167.25 & 162.06 & 152.45 & 137.81 & 111.48 & 87.06 & 70.83 & 70.53 \\
\hline Taste & 39.52 & $<0.0001$ & 160.05 & 141.81 & 138.98 & 127.08 & 129.88 & 101.70 & 78.53 & 80.65 \\
\hline $\begin{array}{l}\text { Overall } \\
\text { acceptability }\end{array}$ & 45.33 & $<0.0001$ & 167.16 & 142.28 & 136.98 & 125.30 & 120.51 & 117.05 & 72.56 & 77.56 \\
\hline
\end{tabular}

${ }^{1}$ Abbreviations: $\mathrm{X}^{2}$, chi square; Pr, probability; $\mathrm{T}_{0}$, oil extracted out of desiccated coconut (DC); $\mathrm{T}_{1}$, oil extracted out of 1\% sesame mixed DC; $\mathrm{T}_{2}$, oil extracted out of $2 \%$ sesame mixed DC; $\mathrm{T}_{3}$, oil extracted out of $3 \%$ sesame mixed DC; $\mathrm{T}_{4}$, oil extracted out of $4 \%$ sesame mixed DC; $\mathrm{T}_{5}$, oil extracted out of $5 \%$ sesame mixed DC; $\mathrm{T}_{6}$, oil extracted out of $7 \%$ sesame mixed DC; $\mathrm{T}_{7}$, oil extracted out of $10 \%$ sesame mixed DC.

Table 2. Ranking order of preference based on mean scores

\begin{tabular}{|l|c|}
\hline Sensory attribute & Ranking order of treatments \\
\hline Color & $\mathrm{T}_{0}>\mathrm{T}_{1}>\mathrm{T}_{5}>\mathrm{T}_{4}>\mathrm{T}_{3}>\mathrm{T}_{2}>\mathrm{T}_{6}>\mathrm{T}_{7}$ \\
\hline Smell & $\mathrm{T}_{0}>\mathrm{T}_{1}>\mathrm{T}_{2}>\mathrm{T}_{3}>\mathrm{T}_{4}>\mathrm{T}_{5}>\mathrm{T}_{6}>\mathrm{T}_{7}$ \\
\hline Taste & $\mathrm{T}_{0}>\mathrm{T}_{1}>\mathrm{T}_{2}>\mathrm{T}_{4}>\mathrm{T}_{3}>\mathrm{T}_{5}>\mathrm{T}_{7}>\mathrm{T}_{6}$ \\
\hline Overall acceptability & $\mathrm{T}_{0}>\mathrm{T}_{1}>\mathrm{T}_{2}>\mathrm{T}_{3}>\mathrm{T}_{4}>\mathrm{T}_{5}>\mathrm{T}_{7}>\mathrm{T}_{6}$ \\
\hline
\end{tabular}

${ }^{1}$ Abbreviations: See Table 1

Table 3. Computed values of $\operatorname{Pr}(H \geq 4)$ for different treatments and sensory attributes ${ }^{1}$

\begin{tabular}{|c|c|c|c|c|}
\hline Treatment & Color & Smell & Taste & Overall acceptability \\
\hline $\mathrm{T}_{0}$ & 0.82 & 0.86 & 0.79 & 0.82 \\
\hline $\mathrm{T}_{1}$ & 0.71 & 0.84 & 0.75 & 0.76 \\
\hline $\mathrm{T}_{2}$ & 0.66 & 0.85 & 0.76 & 0.79 \\
\hline $\mathrm{T}_{3}$ & 0.79 & 0.88 & 0.73 & 0.75 \\
\hline $\mathrm{T}_{4}$ & 0.78 & 0.63 & 0.71 & 0.68 \\
\hline $\mathrm{T}_{5}$ & 0.76 & 0.58 & 0.52 & 0.66 \\
\hline $\mathrm{T}_{6}$ & 0.55 & 0.68 & 0.64 & 0.66 \\
\hline $\mathrm{T}_{7}$ & 0.56 & 0.67 & 0.62 & 0.62 \\
\hline
\end{tabular}

${ }^{1}$ Abbreviation: $\mathrm{H}$, hedonic score of a treatment with respect to a given sensory attribute. For other abbreviations see Table 1. 
$T_{1}$ while the least preferred was either $T_{6}$ or $T_{7}$. Table 1 shows that mean scores of $\mathrm{T}_{6}$ and $\mathrm{T}_{7}$ were not significantly different with respect to smell, taste and overall acceptability.

Odor characteristic of sesame is critical in the formulation of consumer-acceptable oil blends. Therefore, it is important to determine the point at which the majority of the panelists tend to detect the strong odor due to sesame in the oil blends. As point 4 of the seven point Hedonic scale was assigned to indicate neither like nor dislike status, points greater than 4 were considered to indicate likeness while those less than 4 were considered to indicate dislikeness. Based on that assumption, if the headonic score assigned by the panelists is $\mathrm{H}$, then $\operatorname{Pr}(\mathrm{H} \geq 4)$ for a given treatment is a good indicator to measure the probability of likeness by the panelists to that particular treatment with respect to a given sensory attribute. If $\mathrm{H}$ is assumed to be distributed normally, computation of $\operatorname{Pr}(\mathrm{H} \geq 4)$ values could be done using $\operatorname{Pr}(H \geq 4)=\operatorname{Pr}(Z \geq$ $4-\bar{X} / \mathrm{S}$ ), where $\bar{X}$, mean of the scores for a given parameter; $\mathrm{S}$, standard deviation; $\mathrm{Z}$, standard normal distribution.

Computation of $\operatorname{Pr}(\mathrm{H} \geq 4)$ values for all the treatments with respect to all four sensory attributes are presented in Table 3. A $\operatorname{Pr}(H \geq 4)$ value of 0.8 could be taken as the subjective critical value for a given treatment to be satisfactory for the panelists with respect to a particular sensory attribute. Based on this criterion, $\mathrm{T}_{0}, \mathrm{~T}_{1}, \mathrm{~T}_{2}$, and $\mathrm{T}_{3}$ were the only samples which recorded $\operatorname{Pr}(H \geq 4)$ values greater than and equal to 0.8 with respect to odor (Table 3 ). This showed that the majority of the panelists gave higher preference to these four treatments since their odor character is very much acceptable to them. This indicated that the panelists tend to detect the sesame odor in the oil blends from treatment $\mathrm{T}_{4}$ and above. However, with respect to color, taste, and overall acceptability the $\operatorname{Pr}(H \geq 4)$ values were less than 0.80 for all treatments except $T_{0}$. This shows that although smell is better for a given treatment, people might not like the other attributes such as color, taste, and overall acceptability of that particular treatment.

\section{Fatty acid composition and Iodine value (IV) of formulated oil blends}

As a part of the study, fatty acid compositional changes of oil blends were compared to the control sample as shown in the Table 4. In the $\mathrm{T}_{0}$ sample, lauric acid was the dominant fatty acid which came around $50 \%$ of all the fatty acids. After mixing DC with sesame seed there were many changes in the fatty acid distribution pattern. Table 4 clearly indicates that a significantly strong association existed between the proportion of sesame in the oil blends and percentage of all fatty acids excluding capric and palmitic. The increasing proportion of sesame caused significant increases $(p<0.0001)$ in stearic, oleic and lenoleic acids with the concurrent decrease of fatty acids namely caprylic, capric, lauric, and myristic. This changing trend in fatty acid distribution affected the degree of unsaturation which is usually indicated by the iodine value of the oil sample. The regression analysis of the data as presented in Table 4 showed that there was a strong correlation between iodine value (IV) and proportion of sesame (W) in the mixer $\left(\mathrm{IV}=5.201+0.828 \mathrm{~W}\right.$ with $R^{2}=0.9933$; $\mathrm{p}<0.0001)$ and hence, the deviations in IV can be predicted at differing levels of fortifications. Although there was a substantial increase in the degree of unsaturation as indicated by IV, the relative increase in lenoleic acid content was only marginal. At 5\% level of fortification, the increment in lenoleic acid was $9.2 \%$.

\section{Storage stability of formulated oil blends after three months of preparation}

Previous reports already indicated that a sample of CNO which was processed hygienically and preserved from any negative 
Table 4. Iodine value and percentage distribution of fatty acids of different treatments ${ }^{1}$

\begin{tabular}{|l|c|c|c|c|c|c|c|c|c|}
\hline Parameter & $\mathrm{T}_{0}$ & $\mathrm{~T}_{1}$ & $\mathrm{~T}_{2}$ & $\mathrm{~T}_{3}$ & $\mathrm{~T}_{4}$ & $\mathrm{~T}_{5}$ & $\mathrm{~T}_{6}$ & $\mathrm{~T}_{7}$ & $\mathrm{R}^{2}$ \\
\hline Caproic & 0.29 & 0.29 & 0.22 & 0.16 & 0.30 & 0.12 & 0.19 & 0.09 & $0.55(\mathrm{p}<0.0002)$ \\
\hline Caprylic & 6.86 & 6.82 & 6.25 & 6.08 & 7.14 & 5.45 & 5.73 & 4.92 & $0.65(\mathrm{p}<0.015)$ \\
\hline Capric & 5.80 & 5.72 & 5.05 & 5.03 & 5.75 & 5.48 & 4.58 & 4.99 & $0.37(\mathrm{p}<0.269)$ \\
\hline Lauric & 50.34 & 49.88 & 48.48 & 48.98 & 48.54 & 48.20 & 46.64 & 45.88 & $0.93(\mathrm{p}<0.0001)$ \\
\hline Myristic & 19.60 & 19.55 & 19.70 & 19.23 & 18.72 & 18.44 & 18.38 & 18.39 & $0.77(\mathrm{p}<0.0001)$ \\
\hline Palmitic & 7.69 & 7.74 & 7.99 & 7.83 & 7.60 & 8.35 & 8.36 & 8.16 & $0.44(\mathrm{p}<0.448)$ \\
\hline Stearic & 0.83 & 1.22 & 1.85 & 2.08 & 2.30 & 2.54 & 4.00 & 4.38 & $0.96(\mathrm{p}<0.0001)$ \\
\hline Oleic & 5.45 & 5.61 & 7.18 & 7.32 & 7.44 & 7.99 & 8.24 & 8.53 & $0.76(\mathrm{p}<0.0001)$ \\
\hline Linoleic & 3.14 & 3.15 & 3.21 & 3.32 & 3.41 & 3.53 & 3.86 & 4.65 & $0.82(\mathrm{p}<0.0001)$ \\
\hline IV & 5.1 & 6.1 & 7.0 & 8.0 & 8.4 & 9.0 & 10.8 & 13.7 & $0.99(\mathrm{p}<0.0001)$ \\
\hline
\end{tabular}

${ }^{1}$ Each value in the table represents the mean of duplicate analysis. Abbreviation: IV, iodine value; $R{ }^{2}$ Coefficient of determination. For other Abbreviations: See Table 1.

Table 5. Free fatty acid content of oil blends after three months of storage ${ }^{1}$

\begin{tabular}{|c|c|}
\hline Treatment & $\begin{array}{c}\text { Free fatty acid } \\
\text { (as \% lauric acid) }\end{array}$ \\
\hline $\mathrm{T}_{0}$ & 0.03 \\
\hline $\mathrm{T}_{1}$ & 0.03 \\
\hline $\mathrm{T}_{2}$ & 0.03 \\
\hline $\mathrm{T}_{3}$ & 0.05 \\
\hline $\mathrm{T}_{4}$ & 0.05 \\
\hline $\mathrm{T}_{5}$ & 0.07 \\
\hline $\mathrm{T}_{6}$ & 0.10 \\
\hline $\mathrm{T}_{7}$ & 0.11 \\
\hline
\end{tabular}

${ }^{1}$ Each value in the table represents the mean of duplicate analysis. Abbreviation: See Table 1. 
effect coming from extraneous factors could be maintained without deterioration for a period of nearly two years. The changes noticed in free fatty acid content and peroxide values of samples were within the limits specified by the Sri Lanka Standards (Jayasundera et al., 2004; SLS 32:2002). However, by incorporating sesame seed oil into $\mathrm{CNO}$, there can be a little effect on the stability due to the elevated levels of unsaturation. Initially, FFA contents of oil samples were negligibly small and the analysis of samples after three months of storage showed that there was slight increment of FFA content (Table 5). Although sesame seed fortification caused an increase in the degree of unsaturation, the presence of various antioxidative compounds in the sesame oil could help maintain the stability against autooxidation (Namiki, 1995). However, this assumption needs to be confirmed through experimentation. Therefore, further studies are suggested to investigate the effect of antioxidative compounds of sesame on the storage stability of fortified oil blends.

This study attempted to investigate the impact of the different levels of sesame on the flavor changes of $\mathrm{CNO}$ through a micro expeller extraction process. It clearly indicated that the preference of the panelists with respect to each sensory attribute was decreasing with the increasing concentration of sesame in the oil blends. The statistical approach adopted in this study confirmed that the sesame odor in oil blends could be detected at $4 \%$ of sesame fortification in DC.

\section{Acknowledgements}

Financial support from coconut CESS fund is acknowledged. Authors wish to express their gratitude to Dr. C. Jayasekera, Director, Coconut Research Institute, Lunuwila, Sri Lanka for the approval granted for this publication.

\section{Reference}

AOCS, 1987. Official and Tentative Methods of the American Oil Chemists' Society. $3^{\text {rd }}$ edn., American Oil Chemists' Society Champaign, IL, USA.

Baensch, W., Yalegama, C. and Jayasundera, J. M. M. A. 2004. New technologies of coconut processing- part II: Process for production of virgin coconut oil and low fat/high protein coconut flour from coconut kernel, pp. 261-269. In: Proceeding II of the International Coconut Conference-2004, T.S.G. Peiris and C.S. Ranasinghe (Eds.) Coconut Research Institute Lunuwila, Sri Lanka.

Bockisch, M., 1998. Fats and Oils Handbook. AOCS Press, Champaign, IL, USA, pp. 260-267.

Jayasundera, M., Dharmasena, A. and Jayathilake, S. 2004. Report of the Coconut Research Institute for 2004, Lunuwila, Sri Lanka (In press).

Jayasuriya, W. A. J. C. K. 2004. Multi-step crystallization of coconut oil for isolation of medium chain fatty acid enriched fraction. B.Sc. (Agric) Dissertation, University of Peradeniya, Peradeniya, Sri Lanka.

Nathanael, W. R. N. 1966. Moisture and other quality factors of copra, Cey. Cocon. Quart. 17: $1-41$.

PORIM Test Method. 1995. Palm Oil Research Institute of Malaysia, Ministry of Primary Industries, Malaysia.

Deshpande, S. S., Deshpande, U. S. and Salunkhe, D. K. 1996. Sesame oil, In: Bailey's Industrial Oil and Fat Products, Y. H. Hui (Ed.) pp. 457-496, John Wiley \& Sons Inc., New York, USA.

Namiki, M. 1995. Chemistry and physiological functions of sesame. Food Rev. Int. 11: 281. 
Rodrigo, M.C.P., Wijeratne, M.C.P. and Samarajeewa, U. 1999. Deposition of poly aromatic hydrocarbon compounds from different coconut based products in smoke drying of copra, Trop. Agricult. 11: 103-109.

SAS, 1998. Statistical Analysis System User's Guide: Basic Statistics 1998. SAS Institute Inc. Cary, NC, USA.

Silveira, M. S. J., Malini, Y. M., Ranatunge, K., Gunathilake, K. D. P. P. and Samarajeewa, A. D. 2004. Performance evaluation of virgin coconut oil expelling system through a field trial. In: Proceeding II of the International Coconut Conference-2004, T.S.G. Peiris and C.S. Ranasinghe (Ed.) pp. 193-203. Coconut Research Institute, Lunuwila, Sri Lanka.

Specification for Coconut Oil: Sri Lanka Standard 32:2002, Second Revision, Sri Lanka Standards Institution, Colombo. 